\title{
A PÓS-MODERNIDADE E A MORTE DAS METANARRATIVAS: \\ UM DISCURSO DE LEGITIMAÇÃO DO CAPITALISMO
}

\author{
Iron Mendes de Araújo ${ }^{1}$ \\ Dr. Itamar Nunes da Silva ${ }^{2}$
}

\begin{abstract}
RESUMO
Considerando a importância da luta de ideias para a afirmação de um projeto político alternativo ao sistema capitalista mundial e a hegemonia adquirida hoje no ambiente acadêmico bem como na mídia em geral, pelos pensadores da chamada pós-modernidade, o presente artigo visa analisar os pressupostos teóricos das ideias pós-modernas que apontam para um cancelamento das alternativas políticas, na medida em que sepultam as metanarrativas da modernidade. Sem o caminho de uma transformação social radical à vista, os pós-modernos voltam-se para os diversos aspectos da vida social, em especial aqueles que objetivavam maior racionalização, tendo em vista o controle dos indivíduos. Abandonam a pretensão de totalidade que orientava o pensamento moderno, ou seja, suas metanarrativas e desenvolvem uma visão fragmentada da vida cotidiana e dos indivíduos também fragmentados que resulta na prática num discurso de desmobilização das lutas coletivas e de legitimação do capitalismo.
\end{abstract}

Palavras-chave: Capitalismo; Pós-modernidade; Metanarrativas

\section{Introdução}

O presente artigo tem como objetivo analisar e criticar os pressupostos teóricos, políticos e filosóficos da pós-modernidade, a partir da perspectiva da sentença de morte das metanarrativas da modernidade que os pensadores pósmodernos vaticinam. A análise feita procura demonstrar o caráter contraditório das ideias pós-modernas, da sua desesperança, do cancelamento das

1 Graduado em Filosofia e especialista em Filosofia contemporânea pela Universidade Católica de Pernambuco. Mestrando profissional em Filosofia pela Universidade Federal de Pernambuco e professor de Filosofia da Secretaria Estadual de Educação de Pernambuco. Email: iron mendes@hotmail.com

2 Mestre em Ciência Política - UFPE; Doutor em Educação - UFPE; Prof. Do Departamento de Ciências Sociais - UFPB. E-mail: itamarns@gmail.com 
alternativas políticas e de um processo subliminar, e às vezes até aberto, de naturalização do capitalismo, na medida em que falam de uma época pósmoderna, mas sequer admitem uma era pós-capitalista.

Para percorrer o itinerário analítico e crítico utilizamos como referenciais vários pensadores marxistas que dialogam criticamente com as ideias pós-modernas. Para isso, analisamos a herança do iluminismo e de suas promessas de libertação do homem pelo uso da razão, resgatamos a contribuição dos frankfurtianos na denúncia de instrumentalização da razão e narcotização da consciência da classe operária pelo capitalismo através da indústria cultural e reafirmamos, não obstante os percalços da razão iluminista, as ideias da modernidade.

Finalizamos a analise crítica apresentando como alternativa para reavivar o fluxo revolucionário o resgate da teoria marxista e sua metanarrativa como um antídoto, ainda esperançoso, as ideias desesperançosas e fragmentárias da vida social e política difundidas pelos pós-modernistas que tentam consolidar a visão de mundo do sistema capitalista mundial.

\section{Modernidade x pós-modernidade}

Considerando a importância da luta de ideias para a afirmação de um projeto alternativo ao sistema capitalista mundial e, a hegemonia adquirida hoje no ambiente acadêmico e na mídia em geral, pelos pensadores da chamada pós-modernidade, que apregoam a impossibilidade de qualquer projeto coletivo emancipatório do homem, tendo como ponto de partida a crítica aos ideais da modernidade, entendido como aspirações de emancipação humanosocial através do desenvolvimento da razão, cabe situar um pouco as características do pensamento pós-moderno.

Terry Eagleton, em seu livro "As ilusões do Pós-modernismo", da mesma forma que David Harvey e Fredricjamesonrefere-se a pósmodernidade como um período histórico específico, fruto da mudança histórica ocorrida no ocidente, para uma nova fase do capitalismo contemporâneo (fins da década de 60 e início da década 70), caracterizando-a como: 
Uma linha de pensamento que questiona as noções clássicas de verdade, razão, identidade e objetividade, a ideia de progresso ou emancipação universal, os sistemas únicos, as grandes narrativas ou os fundamentos definitivos de explicação. Contrariando essas normas do iluminismo, vê o mundo como contingente, gratuito, diverso, instável, imprevisível, um conjunto de culturas ou interpretações desunificadas gerando um certo grau de ceticismo em relação à objetividade da verdade, da história e das normas, em relação às idiossincrasias e a coerência de identidades (EAGLETON, 1998, p.7).

Para situar esta definição de pós-modernidade, faremos um retorno à herança do iluminismo. Embora reconheçamos que o iluminismo foi, entre outras coisas, a matriz do pensamento liberal, reivindicamos, como marxistas, o seu espólio. O iluminismo foi a bandeira da burguesia europeia em sua luta contra o feudalismo que acabou redundando na revolução francesa e seus ideais de igualdade, liberdade e fraternidade. A bandeira do verdadeiro iluminismo foi empunhada pela nova classe revolucionária, a classe operária, que lutou pela emancipação universal do gênero humano, cuja expressão maior foi a Revolução Bolchevique de 1917 na Rússia.

A razão iluminista, que foi o guia da modernidade, criticava o existente e propunha projetos alternativos de vida. Era uma razão emancipadora, esperançosa com as possibilidades da humanidade. Queria libertar o homem, como afirmava Kant, de sua menoridade pelo uso da razão e salvá-lo de todas as tutelas. Que diferença do ceticismo epistemológico e do derrotismo político da pós-modernidade!

David Harvey, ao discorrer sobre o pensamento da modernidade referia-se à essa visão otimista característica do Aufklärung:

O domínio científico da natureza prometia liberdade da escassez, da necessidade e da arbitrariedade das calamidades naturais. $\mathrm{O}$ desenvolvimento de formas racionais de organização social e de modos racionais de pensamento prometia a libertação das irracionalidades do mito, da religião, da superstição, liberação do uso arbitrário do poder, bem como do lado sombrio da nossa própria natureza humana. Somente por meio de tal projeto poderiam as qualidades universais, eternas e imutáveis de toda a humanidade ser reveladas (HARVEY,2003, p.23).

Pela razão, o homem podia conquistar a felicidade social e política. Essa visão otimista das possibilidades da razão iluminista de propiciar ao homem esperança de um mundo melhor, sofrerá um duro golpe em função de seus resultados concretos. Guerras, desigualdades sociais, catástrofes ambientais, dominação dos países economicamente desenvolvidos sobre os 
demais e a situação de barbárie presentes em algumas regiões do globo, começaram a lançar dúvidas ao projeto de emancipação humano-social através do uso da razão defendido pelo iluminismo.

A primeira crítica vem da "Escola de Frankfurt" que acusa a razão iluminista de ter se transformado numa "razão instrumental" a serviço da exploração e da dominação, da opressão e da violência. Além de o capitalismo ter absorvido e assimilado os indivíduos ao sistema, narcotizando suas consciências através da indústria cultural.

Essa tendência se agravará a partir da segunda metade do século XX com a degeneração das experiências socialistas e a propalada falência desse modelo, como alternativa ao capitalismo. $\mathrm{O}$ mundo não teria mais perspectiva de transformação e finalmente se curvaria ao Status Quo. Estava consumada a vitória do capital. Perry Anderson, referindo-se a essas mudanças afirma que:

O triunfo universal do capital significa mais do que simplesmente uma derrota para todas aquelas forças outrora dispostas contra ele, embora seja isso também. Seu sentido mais profundo esta no cancelamento das alternativas políticas (ANDERSON, 1999, p.108).

De um modo geral, esse é o quadro herdado pelos pensadores da pósmodernidade. O conceito de pós-moderno é a decretação do fim do projeto da modernidade, a falência historicamente constatada de que a razão favoreceria a emancipação do homem.

Sem o caminho de uma transformação social radical à vista, os pósmodernos voltam-se para os diversos aspectos da vida social, em especial aqueles que objetivavam maior racionalização, tendo em vista o controle dos indivíduos. Abandonam a pretensão de totalidade que orientava o pensamento moderno, ou seja, sua metanarrativas e desenvolvem uma visão fragmentada da vida cotidiana e dos indivíduos também fragmentados. Surge, então, a "Política de Identidades”. Ellen Wood descreve essa visão da seguinte forma:

[...] deve estar óbvio que o fio principal que perpassa todos esses princípios pós-modernos é a ênfase na natureza fragmentada do mundo e do conhecimento humano. As implicações políticas de tudo isso são bem claras: o self humano é tão fluido e fragmentado (o "sujeito descentrado") e nossas identidades, tão variáveis, incertas e frágeis que não pode haver base parasolidariedade e ação coletiva fundamentada em uma "identidade" social comum (uma classe), em uma experiência comum, em interesses comuns (WOOD ; FOSTER,1999, p.13). 
O ceticismo teórico e prático advindo das ideias pós-modernas é assustador. É uma ode ao irracionalismo e ao capitalismo, um abandono do sujeito, um verdadeiro anti-humanismo por ver na ação humana apenas a submissão aos mecanismos de controle da estrutura sócio-econômica do capital. Não é à toa que esses pensadores tenham decretado a morte do marxismo e o fim da história. Com a devida vênia a Marx, poderíamos afirmar que "um espectro ronda os pós-modernos, o espectro do comunismo". A própria teoria marxista é o antídoto ao ceticismo pós-moderno. Vejamos o que Ellen Wood escreve a respeito disso:

De qualquer modo, vivemos hoje um momento histórico que, mais que qualquer outro, requer um projeto universalista. Trata-se de um momento histórico dominado pelo capitalismo, o sistema mais universal que o mundo já conheceu. Tanto por ser global quanto por penetrar em todos os aspectos da vida social e do ambiente natural. (...) a realidade social do capitalismo é "totalizante" em formas e graus sem precedentes. Sua lógica de transformação de tudo em mercadoria, de acumulação, maximização do lucro e competição satura toda a ordem social. E entender esse sistema "totalizante" requer exatamente o tipo de "conhecimento totalizante" que o marxismo oferece e os pós-modernistas rejeitam (WOOD ; FOSTER, 1999, p.19).

É curioso também, como o pós-modernismo se rende ao capitalismo e rejeita o projeto iluminista, acusando-o de crimes que a rigor deveriam ser atribuídos ao próprio capitalismo.

John Foster, em seu artigo "Em defesa da História", tratando das contradições do pós-modernismo, afirmaque "A ironia do pós-modernismo é que, enquanto alega ter transcendido a modernidade, abandona desde o início todaesperança de transcender o capitalismo em si e de ingressar em uma era pós-capitalista" (WOOD; FOSTER, 1999, p. 205).

\section{Conclusão}

Podemos concluir que o projeto da modernidade, como dizia Habermas, ainda não foi cumprido. O potencial para a racionalização do mundo não esta esgotado. Faz-se necessário, pois, o resgate dialético, com a devida crítica "a razão instrumental", da visão de mundo da modernidade para dar um choque de racionalismo no irracionalismo pós-moderno, reafirmando o planejamento de ordens sociais ideais. Precisamos de novas luzes alicerçadas 
nas bases da teoria marxista, para se contrapor à teoria conformista e desesperançosa difundida pelos pós-modernistas.

Estamos convencidos de que só a razão é libertadora enquanto o irracionalismo é repressivo e perigoso. É necessário declarar guerra aos pressupostos teóricos dos pós-modernistas, denunciando seu caráter ideológico de naturalização do capitalismo. Só assim, será possível reconstruir o "sujeito histórico" e dar perspectivas a milhões de sujeitos militantes de reavivarem o fluxo revolucionário, outrora tão vivo, em direção a uma sociedade que seja alternativa ao capitalismo.

Para finalizar, concluímos com a frase de João Amazonas: "Assim será o século XXI. Em seus começos, haverá sombras e luzes, mais sombras do que luzes. Depois, o quadro se inverterá. A humanidade viverá tempos de grandes esperanças" (AMAZONAS, 1999, p. 44).

\section{Referências}

AMAZONAS, João. Os desafios do socialismo no século XXI. São Paulo: Ed. Anita Garibaldi, 1999.

ANDERSON, Perry. As origens da pós-modernidade. Trad. de Marcus Penchel. Rio de Janeiro: Jorge Zahar. Ed,1999.

EAGLETON, Terry. As ilusões do pós-modernismo. Trad. de Elisabeth Barbosa. Rio de Janeiro: Jorge Zahar ed., 1998.

HARVEY, David. Condição pós-moderna. 12. ed. Trad. de Adail Ubirajara Sobral e Maria Stela Gonçalves. São Paulo: Loyola, 2003.

WOOD, Ellen Meiksins; FOSTER, John Bellamy (orgs.). Em defesa da história: marxismo e pós-modernismo. Trad. de Ruy Jungmann. Rio de Janeiro: Jorge Zahar, 1999. 